\title{
ESTUDO DA TRANSFERÊNCIA DE CALOR EM BLOCOS CERÂMICOS
}

\author{
R.F. COSTA ${ }^{1}$, A.D. FERREIRA ${ }^{2}$, J.J.S. NASCIMENTO ${ }^{3}$, C.L. ARAÚJO ${ }^{4}$, K. N. DOS \\ SANTOS $^{5}$ \\ ${ }^{1}$ Universidade Federal de Campina Grande, Pós Graduação em Engenharia de Processos \\ ${ }^{2}$ Universidade Federal de Campina Grande, Departamento de Engenharia Química \\ ${ }^{3}$ Universidade Federal de Campina Grande, Departamento de Engenharia de Materiais \\ ${ }^{4}$ Universidade Federal de Campina Grande, Departamento de Engenharia Elétrica \\ ${ }^{5}$ Universidade Federal de Campina Grande, Departamento de Engenharia de Petróleo \\ E-mail para contato: ranierengenharia.costa@gmail.com
}

\begin{abstract}
RESUMO - No ambiente onde acontece transferência de calor deve-se ter um adequado controle das condições psicrométricas do ar, de modo a evitar danos estruturais irreversíveis. Sendo assim, objetivo dessa pesquisa é estudar através da simulação computacional a transferência de calor em blocos cerâmicos em uma estufa de secagem. Para avaliar o comportamento da temperatura no interior do bloco cerâmico foi empregado o software Ansys Workebench CFX 16. Assim, no estudo são evidenciados e analisados os perfis bidimensionais de temperatura no interior do bloco cerâmico, sendo possível identificar as possíveis regiões em que ocorre riscos de trincas, deformações ou fraturas.
\end{abstract}

\section{INTRODUÇÃO}

No ambiente onde acontece transferência de calor e/ou massa deve-se ter um adequado controle das condições psicrométricas do ar, de modo a evitar danos estruturais irreversíveis, contribuindo para perdas de produtos e aumento de custos para as indústrias nacionais e locais e logo diminuindo empregos e renda.

Durante o processo de secagem, elevados gradientes de umidade e temperatura no interior do sólido podem causar defeitos irreversíveis no mesmo, como aparecimento de trincas, deformações e empenamentos. Neste contexto, é essencial conhecer o mecanismo de transferência de calor e os efeitos da secagem em seu controle, uma vez que estes alteram as propriedades físicas e químicas do produto, e tais alterações afetam sensivelmente o processo (DaPaz,2011). O tijolo é seco em câmaras a temperaturas que oscilam normalmente entre $30 \mathrm{e}$ $70^{\circ} \mathrm{C}$, o tempo de secagem é variável e poderá oscilar em torno de 16 horas, conforme a $\mathrm{ABC}$ - Associação Brasileira da Cerâmica (2007).

Assim com o desenvolvimento de pesquisas e modelos computacionais para solução de problemas reais, tipo a secagem, é possível obter por simulação, com rapidez e efícácia, condições otimizadas para o processo em estudo, minimizando no caso as perdas do produto.Com isso, a proposta desse trabalho é apresentar uma modelagem matemática tridimensional da transferência de calor em sólidos paralelepípedos, na qual represente fielmente o fenômeno de secagem, permitindo verificar áreas mais favoráveis a tensões 
mecânicas e térmicas associadas a possíveis danos estruturais, tais como trincas e deformações utilizando o software Ansys Workebench CFX16 para simulações numéricas.

\section{MODELAGEM MATEMÁTICA}

O processo de secagem se dá dentro da estufa envolvendo dois mecanismos de transferência de calor, convecção e condução . O primeiro se dar devido a transferência de calor que ocorre entre a superfície do bloco e o movimento do fluido quando eles estão com diferentes temperaturas; o segundo ocorre por meio de um gradiente de temperatura da superfície até o cento do bloco. O modelo foi dividido em dois domínios, um sólido e um fluído, como mostrado na Figura 1.

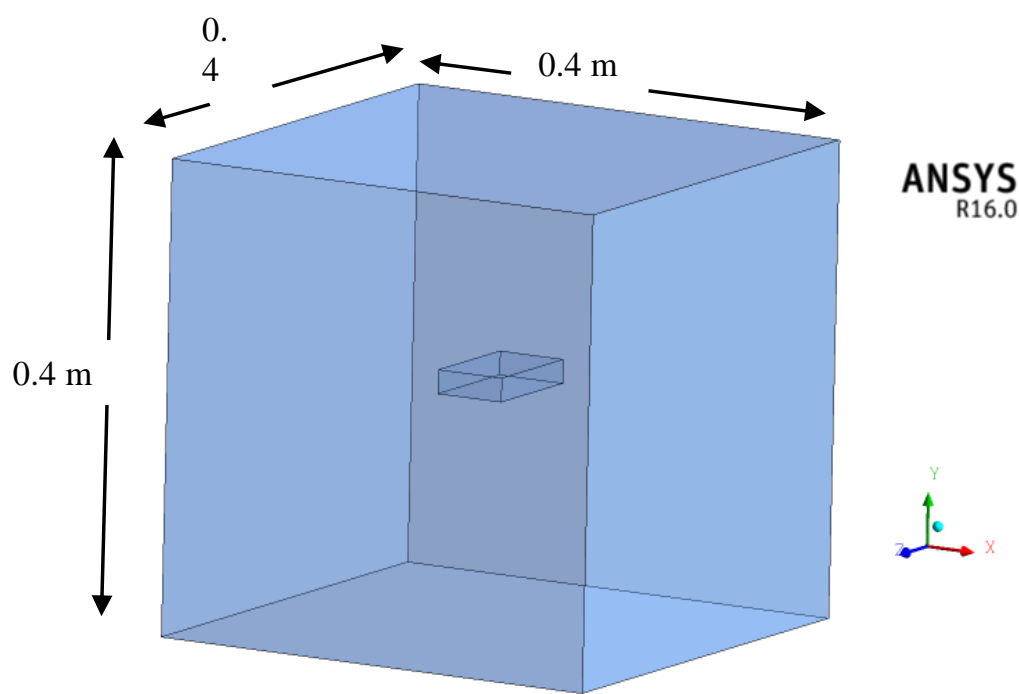

Figura 1 - Configuração geométrica do estudo.

Para a transferência de calor no bloco sólido foi considerado que as propriedades termo físicas são constantes, durante todo o processo de difusão; o sólido é homogêneo e isotrópico; a distribuição da temperatura é uniforme no início do processo; o coeficiente de transferência de calor é assumido como constante em todo o processo. A partir dessas considerações, as simulações foram realizadas o software Ansys Workebench CFX na qual foi utilizada a seguinte equação(Equação 1).

$$
\frac{\partial(\rho e)}{\partial t}+\nabla \cdot(\rho U e)=\nabla \cdot(\lambda \nabla T)-p \nabla \cdot U+\tau: \nabla U+S_{E}
$$

Foram adotadas as seguintes condições de contorno:

- Seção de entrada: velocidade do ar prescrita de $0,1 \mathrm{~m} / \mathrm{s}$ a $100{ }^{\circ} \mathrm{C}$

- Seção de saída: 0 atm

- Seção de parede: adiabática e sem rugosidade 


\section{RESULTADOS E DISCUSSÃO}

Foram construídas quatro malhas com quantidades diferentes de números de elementos hexaédricos. A análise de dependência de malha foi realizada, sendo escolhida a de números de nós igual a 18796. A configuração geométrica do bloco está evidenciada na Figura 2.

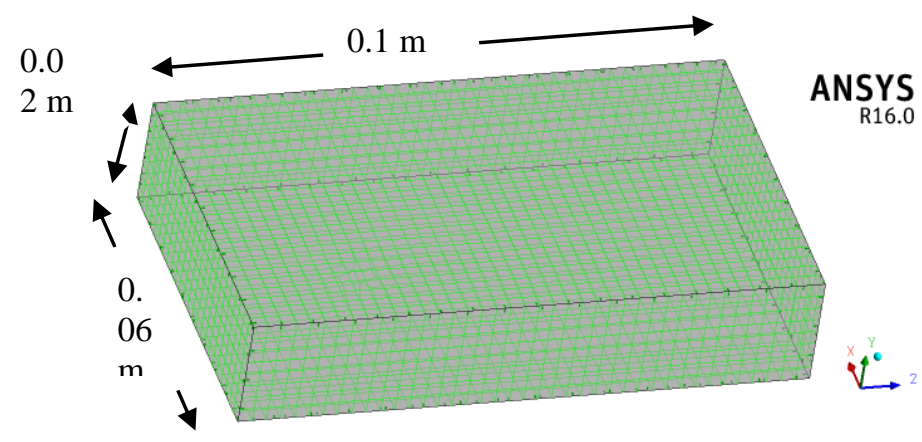

Figura 2-Malha do bloco

$\mathrm{Na}$ Figura 3, verifica-se que os maiores gradientes de temperatura estão localizados nas regiões próximas aos vértices do tijolo, uma vez que estas regiões estão em contato mais intenso com o ar de secagem, com isso as mesmas são mais susceptíveis ao aparecimento de trincas e deformações, que concordam com a afirmação de Cadé et all (2005) e Da Luz (2011).
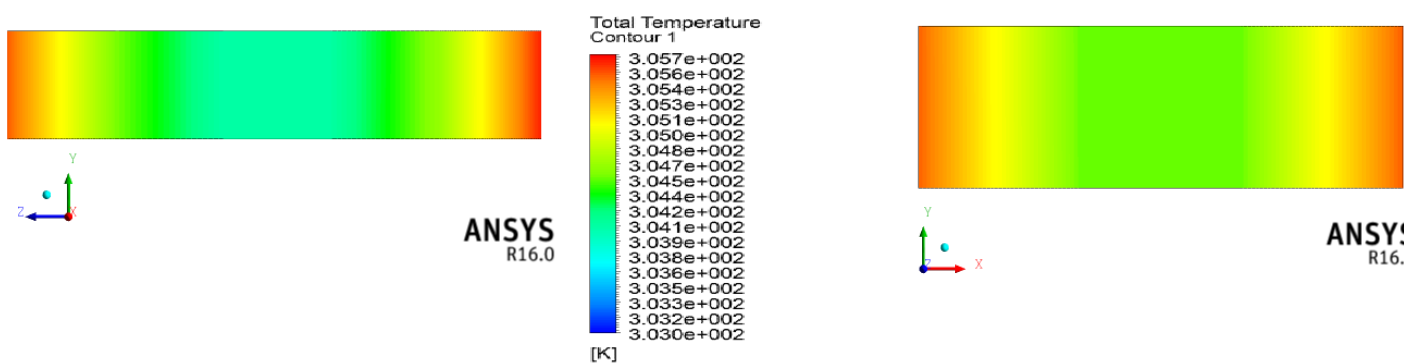

ANSYS
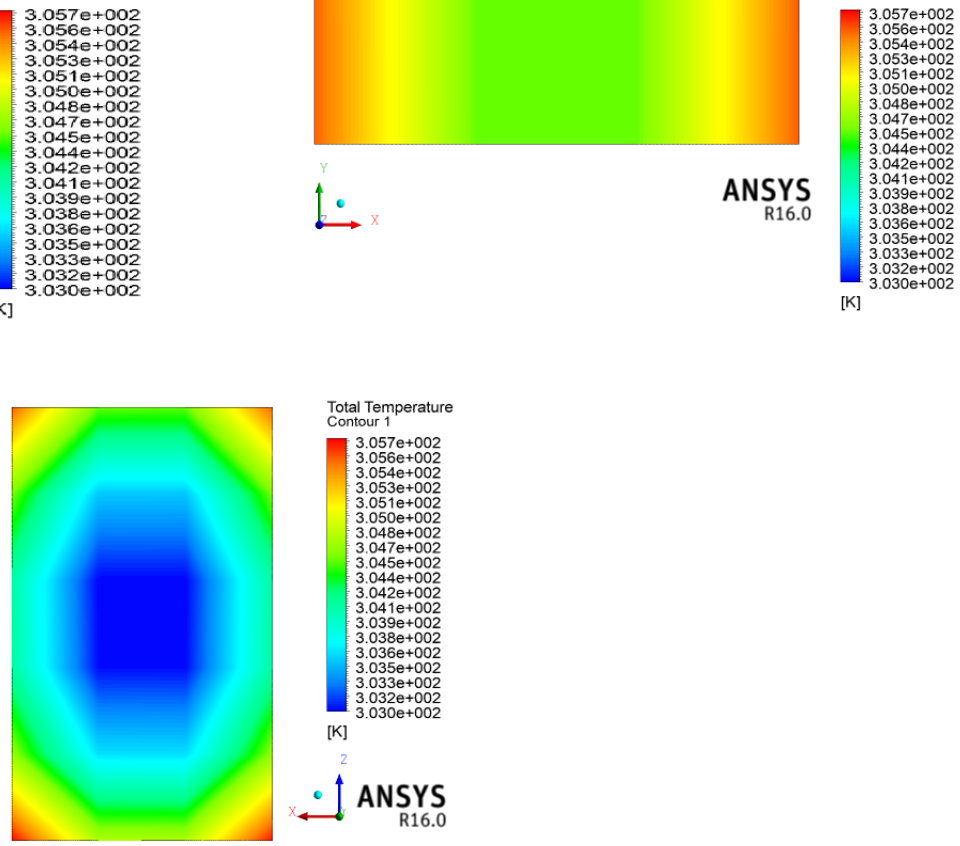


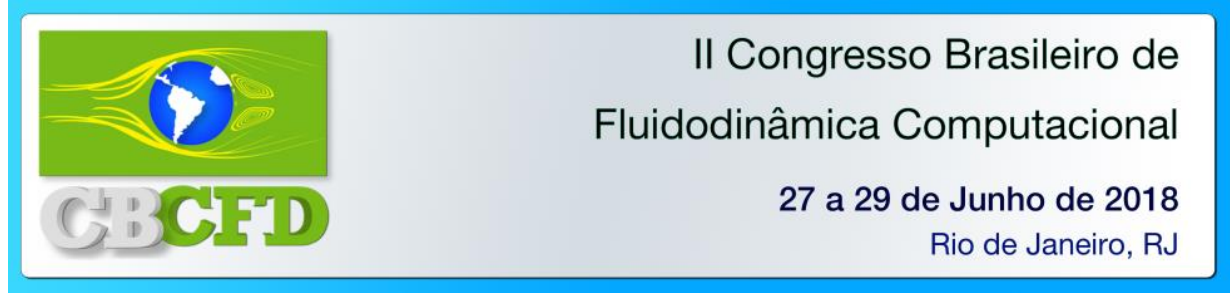

Figura 3 - Temperatura contida no interior do paralelepípedo sólido em 20 min

Características inerentes à camada limite dificultam a transferência de calor nas outras regiões do tijolo. Com o passar do tempo esta diferença diminui, mas as bordas sempre estão à temperaturas mais elevadas, de acordo com o que apresenta o trabalho de Muregesan et all (2001).

Para evaporação mais rápida, a área próxima as extremidades tende a ter deformações acentuadas. Isso leva a uma possível existência de rachaduras, fissuras e deformações, originadas por gradientes de temperatura que podem alterar a qualidade do material no final do processo. Diante do exposto, essa é a importância do conhecimento do perfil de temperatura dentro do material.

\section{CONCLUSÃO}

A cerca dos resultados obtidos, concluiu-se que o modelo de simulação de transferência de calor foram capazes de predizer o fenômeno de secagem, podendo afirmar que o tijolo seca a partir de suas extremidades para o centro por causa da influência do calor, apresentando riscos de danos estruturais como trincas e deformações nas regiões dos vértices.

\section{NOMENCLATURA}

$\rho=$ densidade da massa

$U=$ temperatura

\section{REFERÊNCIAS}

ASSOCIAÇÃO BRASILEIRA DA CERÂMICA. Processo de Fabricação do tijolo. Disponível em: http://www.abceram.org.br/ . Acessado em março, 2018.

CADÉ, M. A; NASCIMENTO, J. J. S.; LIMA, A. G. B. de. Secagem de Tijolos Cerâmicos Vazados: Uma Aproximação por Volumes Finitos. Revista Matéria. Rio de Janeiro, v.10, n.3, p. $443-453,2005$.

DA LUZ, E.W. O estudo da transferência de calor no processo de secagem de tijolos maciços II Congresso Nacional de Educação Matemática. Unijuí- RS, Junho de 2011.

MUREGESAN, K.; SURESH, H.N.; SEETHARAMU, K.N.; NARAYANA, P.A.A.;SUNDARARAJAN, T. A theoreticalmodelofbrickdrying as a conjugate problem.Internationa IJournal of Heat and Mass Transfer, v. 44, p. 4075 - 4086, nov. 2001. 